\title{
The Application of 3S Technology to the Tsukuba Bailin Landscape Project
}

\author{
http://dx.doi.org/10.3991/ijoe.v9i4.2935
}

\author{
Hao XU \\ Nanjing Forestry University, Nanjing, China
}

\begin{abstract}
The purpose of this paper is to investigate the method and process of using $3 \mathrm{~S}$ technology on a landscape engineering project. Through a case study on the Bailin landscape construction project in Tsukuba, Japan, this paper argues that strengthening the drafting capabilities of $3 S$ technology (e.g., comprehensive database management, mapping, landscape simulation, and data updating) will create the type of integrated platform for engineering design and management needed to increase the efficiency of landscape engineering projects.
\end{abstract}

Index Terms-3S; GIS; GPS; RS; Landscape Project.

\section{INTRODUCTION}

Landscape engineering, a vital component of architectural engineering, is based on the principles of sustainable development and provides a comprehensive arrangement of materials and space. The process of landscape engineering and construction should be inexorably linked to the processing of geospatial information.

Although CAD provides a convenient and accurate simulation of engineer-generated models, it is limited in its ability to handle the collection, analysis, and processing of spatial information. Indeed, the recent development of $3 \mathrm{~S}$ technology systems(i.e., systems that incorporate GPS, RS, and GIS) for the representation of spatial information has decreased the traditional reliance on CAD systems in computer-aided drafting and design. Given $3 \mathrm{~S}$ technology's ability to collect and process information, generate models, and integrate technology, the increased use of this technology will greatly increase the efficiency of engineering projects [1].

$3 \mathrm{~S}$ is the collective term for GPS (global positioning system), RS (remote sensing), and GIS (geographic information systems) technology. GPS records the location and attributes of an object and converts information to a digital format for storage, processing, and export. RS measures surface features with high precision in all weather conditions and provides the source information for GIS. GIS, a spatial database management system, preserves and manages spatial and attribute data obtained from GPS, RS, and other media. Through various methods of superposition, proximity analysis, and network analysis, GIS recognizes and evaluates objective landscape characteristics and patterns of land use [2]. It can also forecast changes in landscapes and produce virtual landscape simulations.

$3 \mathrm{~S}$ has been widely used for the management of urban and rural natural resources, but it has rarely been applied in the field of landscape engineering. Throughout the
Bailin Park Construction Project, which is located near the Japanese city of Tsukuba, the author utilized $3 \mathrm{~S}$ integration technology from the initial surveying and design phase through the construction and management. This paper summarizes the project, its characteristics, and the application of $3 \mathrm{~S}$ technology to the project [3].

\section{PROJECT SUMMARY}

The project was based at the southern foot of Mount Tsukuba in Japan's Kanto Plain on a hillside with an elevation of about 250 meters and a surface area of 4.5 hectares. In 1965, 30 types of plum trees and a few cherry trees were planted on the site; the plum trees number close to 1000 , and the park became widely known as a popular leisure spot. However, due to a long-term lack of maintenance, the infrastructure had degraded. During this period, the park had become overgrown with weeds, and the trees lacked the care necessary to stave off serious diseases and pests. As a result, many plum trees died, which contributed to the general loss of the park's restive atmosphere. Under these circumstances, the laboratory of Professor Masakazu Suzuki of Tsukuba University was commissioned by the Tsukuba city government to take responsibility for the landscape engineering design, to restore the park, to reverse the trend of landscape degradation, and to restore the park's position as a leisure and tourism destination.

Because of the dense growth of wild plants blocking the vistas, the first consideration was to restore the vistas and to revitalize the main landscape flora. An accurate accounting of the plants, topography, structures, and paths was required. Originally, the grounds were not formally planned, so there was no base map from which to work. After taking into account factors such as cost and convenience, GPS and RS technology were employed in the initial stages of the engineering. The data collected using GPS and RS were subsequently processed on the GIS platform. The data set was then converted into an electronic document that could be used by CAD for drafting. Using GIS, the trees were classified into those that should be cut down, pruned, or preserved. Other features were ascertained, such as the number and location of pathways, landmarks, and buildings. The vector files produced by GIS were input into CAD, which was used to produce a construction design plan. At the same time, the information that had been collected by GPS regarding the state of basic structures and plants was imported into a database so that it could be used by managers and engineers during subsequent projects. The design produced by the CAD program was transferred back into GIS, which was used to create a landscape simulation that was in turn the basis for an online virtual experience. 
TABLE I.

THE HARDWARE AND SOFTWARE

\begin{tabular}{|c|c|c|}
\hline & Name & Purpose \\
\hline \multirow{3}{*}{ Hardware } & $\begin{array}{l}\text { PC running } \\
\text { Microsoft } \\
\text { Windows }\end{array}$ & $\begin{array}{l}\text { Provide a basic run-time environment } \\
\text { for } 3 \mathrm{~S} \text { and the design process }\end{array}$ \\
\hline & Scanner & $\begin{array}{l}\text { Input other data related to the basic } \\
\text { drawing and convert it to raster images }\end{array}$ \\
\hline & $\begin{array}{l}\text { DGPS } \\
\text { Equipment } \\
\text { from } \\
\text { Trimble }\end{array}$ & $\begin{array}{l}\text { Collect location and basic attribute data } \\
\text { on the area, such as trees, pathways, } \\
\text { streams, buildings, and other } \\
\text { infrastructure. }\end{array}$ \\
\hline \multirow{6}{*}{ Software } & Pathfinder & GPS Data Processing \\
\hline & MapInfo & $\begin{array}{l}\text { Apply superposition analysis to data, } \\
\text { create GIS botanical database, create } \\
\text { retrieval system, create project maps }\end{array}$ \\
\hline & TNTMips & $\begin{array}{l}\text { Basic calculations (e.g., computing } \\
\text { surface areas and the length of } \\
\text { pathways), compositing 3D models, } \\
\text { section mapping, high-level retrieval, } \\
\text { network analysis }\end{array}$ \\
\hline & Photoshop & $\begin{array}{l}\text { Compositing IKONOS satellite } \\
\text { imagery }\end{array}$ \\
\hline & Mini-CAD & Create designs \\
\hline & Excel & Create botanical database \\
\hline
\end{tabular}

\section{HARDWARE, SOFTWARE, AND DATA}

This project used Differential GPS (DGPS) products from the Trimble Corporation, which included signal receivers (e.g., the GPS receiver and the beacon receiver), a data acquisition device, and various antennae (e.g., GPS and beacon receiving antennae). To calculate the position of objects, the GPS beacon receiver receives satellite signals at a frequency of once per second. At the same time, we also used differential beacon technology, which receives signals emitted from Japanese Coast Guard beacon stations. Using both of these technologies, we were able to pinpoint a location to within one meter. After calculating a position, we were able to store and illustrate the layout of the coordinates on the screen of the data acquisition machine. In fact, with its ability to input and record an object's location and characteristics, the data acquisition machine was used as the primary portable computer for the data collection software.

In addition to the GPS equipment used to collect location and basic attribute information, we procured IKONOS satellite imagery (with a resolution of $1 \mathrm{~m}$ ) to more accurately grasp the surface characteristics of the site (for the advantages and use of such photos, please see the cited material). We purchased images in four bands: red, green, blue, and infrared. Photoshop was used to composite the satellite images [4]. Subsequently, the satellite images and GPS data were analyzed and processed through the GIS software MapInfo and TNTMips. In addition, we mainly used the GIS software Path Finder for GPS data processing. GIS and image processing software was run on a PC with a Windows operating system. In addition to the IKONOS satellite images, we also used a 1/2500-scale city diagram produced by the Geographical Survey Institute of Japan for data on the area; this diagram was scanned into a digital format and converted into a raster image.

\section{TASK PROCESSES}

\section{A. Assigning Coordinates}

As a base map, this project used a 1/2500-scale city plan produced by the Geographical Survey Institute of Japan. Using a scanner, we converted this plan into a raster image and saved it as a TIFF file. This image was processed in Photoshop, which was used to correct the balance and remove anomalies. Then coordinates were assigned in MapInfo. We used the general-purpose coordinates released by the Geographical Survey Institute of Japan (Japan Plane Orthogonal Coordinate System, 9th District) for the project.

\section{B. Satellite Image Processing}

Through the Japan Space Imaging Corporation, we procured 4 bands of satellite images taken by IKONOS. The images were composited in Photoshop to give various true-color and false-color photographs. The photos were assigned the same coordinates as the base map by entering them into MapInfo and TNTMips. Geometric corrections were made. Using TNTMips, we classified different surface objects in a first step toward determining surface characteristics [5] [6].

\section{DGPS Data Collection and Input}

Using DGPS equipment, we fixed the positions of individual features (e.g., trees, pathways, streams, bridges, landmarks, and other structures) and checked them against the base map coordinate system. When determining the positions of trees, we mostly collected the locations of plum trees and cherry trees. During this process, we collected basic characteristics, such as the height of each tree, the dimensions of each tree canopy, the height and use of each building.

We created a layer for each feature (e.g., trees, paths, streams, bridges, landmarks, structures, etc.) by using a uniquely colored point, line, or polygon to represent each feature. We then converted the document into a DXF file for storage and transferred it into the GIS software.

\section{Building a GIS Structure}

A GIS layering structure model was formed by entering the above-mentioned base map, satellite imagery files, and DXF file into MapInfo and TNTMips (Figure 1). A unified coordinate system (from the 9th District of the Japan Plane Orthogonal Coordinate System) was used to create this model. Because of construction, disease, pests, and other factors, changes had occurred in the paths, basic facilities, and trees. Data on landscape variation was gathered by DGPS and can be visualized in the GIS layering structure compositing mode.

\section{E. Topography Simulation}

The intricate drawings in the city plans were previously the only source of basic topography data. However, because the scale is so large, there is no way to accurately grasp the topography of the area. Data regarding a given location were determined by DGPS and include horizontal coordinates, vertical coordinates, and elevation data. An accurate 3D model was generated by transferring the coordinate data into TNTMips. Using the 3D model, we can calculate the surface area, the slope, and the distance between two arbitrary points, as well as the volume of the earthworks. This allows us to generate section diagrams of 
the basic terrain that are helpful during preparations for construction.

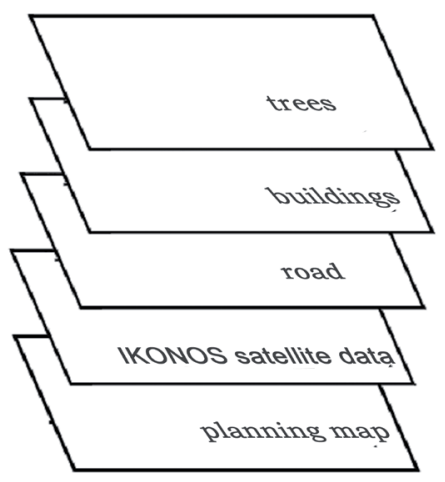

Figure 1. GIS Layering structure.

\section{F. Engineering Design}

The engineering design was completed using CAD software. The DXF format, the standard format for CAD, is used to store coordinate data and to establish a data exchange channel between CAD images and the GIS platform. The data involving layers for streams, bridges, pathways, and the remaining trees was extracted from GIS and converted into a DXF file, which can serve as a standard blueprint for engineering projects.

\section{G. Plant Database}

The plant species in the area are numerous, especially the world-famous plum trees. The key indicator of the project's success is the protection and utilization of the plum trees and the area's other landscape resources. Therefore, it was necessary to establish a botanical database. MapInfo was the most convenient method to create the database. Botanical attribute information derived from DGPS (e.g., tree height, canopy dimensions, tree type, diseases, and pests) was converted into a text file and imported into MapInfo, which created a botanical database. This botanical database was directly linked to the botanical distribution map. The database had retrieval and selection functions and could be displayed concurrently on the map window of MapInfo.

The database, when exported to an Excel file format, can be used as a guideline for any subsequent management, pruning, felling, and disease and pest treatment of the plants [7].

\section{H. Simulating Images and a Virtual Experience}

In addition to making topographic simulation possible, the collecting and processing of location data on paths, basic facilities, structures, and trees in TNTMips allows us to directly simulate landscape changes (the pre- and postproject state). When these simulation results are stored as image files, GIS technology provides the online visitor with a virtual experience of the area's environment.

\section{SUMMARY}

This study demonstrated that $3 \mathrm{~S}$ technology (e.g., topographic simulation, 3D display, and database management) is highly useful in every stage of a landscape engineering project, even though the graphics capability of GIS software still does not compare to CAD.

$3 \mathrm{~S}$ technology is developing into a novel platform for the planning and managing of landscape projects and will become much more powerful as the graphics software for GIS and the user interface improve [8] [9]. Certainly, the functions lacking in CAD programs, such as database management, map creation, and landscape modeling, will also improve and be integrated with newer methods of RS and GPS data input. Ultimately, 3S technology will greatly increase the efficiency of landscape engineers.

\section{REFERENCES}

[1] F. Steiner, The Living Landscape: An Ecological Approach to Landscape Planning, 2nd ed., McGraw-Hill Professional, 2000, pp. 189-209.

[2] T.Y. Chou,T. C. lei, S. wan, L. S. Yang, "Spatial knowledge database as applied to the detection of changes in urban land use," International Journel of remote sensing, 2005, 26, pp. 3047-3048.

[3] Y. Tutui, "Environmental information analysis with GIS," Landscape Research Japan, 2001, 64(3), pp. 216 - 219. http://dx.doi.org/10.5632/jila.64.216

[4] G. Dial, H. Bowen, and F. Gerlach, "IKONOS satellite, imagery, products," Remote Sensing of Environment, 2003, 88, pp. 23-36. http://dx.doi.org/10.1016/j.rse.2003.08.014

[5] K. Segl, H. Kaufmann, "detection of small objects from high resolution panchromatic satellite imagery based on supervised image segmentation," IEEE Transactions on Geoscience and Remote Sensing, 2001, 39, pp. 2080-2083. http://dx.doi.org/10.1109/36.951105

[6] K. Shailesh, G. Joydeep, and M. C. Melba, "Best-bases feature extraction algorithms for classification of hyperspectral data," IEEE Transaction on geoscience and Remote sensing, 2001, 39, pp. 1368-1379.

[7] S. Theodoridis, K. Koutroumbas, Pattern recognition, 2nd ed., NewYork: Academic Press, 2003, pp. 161-180.

[8] M. Suzuki, Geographical Information Syatems for landscape Architecture. Tokyo: Soft Science, Inc. 2003, pp. 27-45.

[9] H. Xu and M. Suzuki, "Application of RS,GIS and GPS technology on green land analysis and planning," Journal of Nanjing Forestry University, 2005, 5, pp. 115-118.

\section{AUTHORS}

H. X. Author is with the College of landscape architecture, Nanjing Forestry University, Nanjing, CO 210037 CHINA (e-mail: xuhao73@vip.163.com).

This article is an extended and modified version of a paper presented at the 2012 International conference on Applied Science and Engineering Innovation (ASEI2012), held in Beijing, China, December 2012. Submitted 21 June 2013. Published as re-submitted by the author 23 July 2013. 